\title{
Exploring Personality Disorders: A Psycho analytical Overview of Paula Hawkins' The Girl on the Train
}

\author{
Hima S Madhu, Arsha Vincent S
}

Department of English, Government Arts College, Trivandrum, India

Received: 10 May 2021; Received in revised form: 03 Jun 2021; Accepted: 16 Jun 2021; Available online: 21 Jun 2021 (C2021 The Author(s). Published by Infogain Publication. This is an open access article under the CC BY license (https://creativecommons.org/licenses/by/4.0/).

\begin{abstract}
Psychoanalysis, one of the modern theories, that are employed in English literature to interpret the hidden meaning of a literary text. It also helps to examine the innate conglomerate of the writer's personality. It also helps to understand the factors that contribute to his experience from birth to the period of writing a book. Paula Hawkins represented the toxic effects of personality disorders in The Girl on the Train through Megan. Megan experienced Post Traumatic Stress Disorder, Obsessive-Compulsive Disorder, Histrionic Personality disorder and antisocial personality disorder. Thus, Paula Hawkins had expressed it through an ambiguous style of narration by the novel The Girl on the Train.
\end{abstract}

Keywords-American dream, posttraumatic stress disorder, psychoanalysis, recession.

\section{INTRODUCTION}

Paula Hawkins, Zimbabwe-born British author, was a financial journalist that was popular in Britain during the Recession period. She published romantic anti comedies under a pen name, Amy Silver before she could gain a reputation for her best psychological thriller, The Girl on the Train (2015). As a child, she had a curiosity about writing stories. She enjoyed writing, but never showed them to anyone. She wrote romantic comedies based on the force from the commission. She was influenced by Kate Atkinson, Margaret Atwood, Donna Tartt's and Pat Barker. While reading the work of Donna Tartt's The Secret History, her eyes opened to the possibility of the psychological thriller. To her, Margaret Atwood was an author who can write about the big, terrifying subject in an extraordinarily readable and enjoyable way. Thus, she turns to psychological thrillers by her interest. Her first psychological Thriller was The Girl on the Train. It was a novel framed under the themes of memory, unreliable narrators and an obsession with the dark and macabre. This novel is complex because of its interweaving narratives and shifting perspectives. In an interview she says that all characters in the novel have secrets to protect. Her famous work includes The Girl on the Train (2015), into the water
(2017) and The Reunion (2013). SJ Watson, an English author, after analysing the novel The Girl on the Train says 'Gripping, enthralling -a top-notch thriller and a compulsive 7 read'. Silas House, Rainbow Rowell, Maria Issac and Iris Bravo and Gillian Flynn were the contemporaries of Paula Hawkins.

The Girl on the Train, a story about three women, represents the life of Megan, Rachel and Anna. Rachel had spent the last few years stumbling through life in a booze filled depression ever since her husband left her for another woman. Anna is the woman that Tom, Rachel's ex husband, cheated on Rachel. Megan is the woman whom Tom had an affair with when he was married to Anna. So, all those three women in the novel experiences traumatic events. In Theory of Literature by Rene Wellek and Austin Warren, they say that according to Freud, the artist is originally a man who turns from reality. He is originally a man who turns from reality because he cannot come to terms with the demand for the renunciation of instinctual satisfaction. 


\section{RECESSION AND PSYCHOANALYSIS}

Psychoanalysis, one of the modern theories, is employed in English literature to interpret the hidden meaning of a literary text. It also helps to examine the innate conglomerate of the writer's personality. It also helps to understand the factors that contribute to his experience from birth to the period of writing a book. The psychoanalysis movement is championed by Sigmund Freud. Psychoanalysis is intensified on motives. It is concentrated on unnoticed or disguised motives which help to clarify literature on two levels, the level of writing itself and the level of character action within the text. The notion of psychoanalysis was firstly emphasized in The Interpretation of Dreams (1900), by Sigmund Freud. Freud analyzed Sophocles' Oedipus Rex and Shakespeare's Hamlet and find out the concept of Oedipus Rex. His other work Creative Writers and Daydreaming enlarged the connection between literature and psychoanalysis. Psychoanalytic criticism gives importance to the author, characters, audience and text. It deeply analyses the author's literary works, the character's behaviour , motivations, the audience's appeal of the work for those who read it, the role of language and symbolism in the works of authors. Gone Girl excavates the improbability of inexhaustible love because of America's consumer culture that fosters narcissistic selfishness. These novels deal with how patriarchal forces present inconceivable demands on relationships due to self-seeking behaviour. The toxic effects of consumer narcissism can be observed when in the relationship between Nick and Amy. It transformed them into two consumer subjects. This creates an internal conflict between an individual's desire to find an authentic self and the continual pursuit of self-image.

Recession is a decline or stagnation in economic growth. The Great Recession started in December 2007. Another name of the Great Recession is subprime mortgage crisis. It was a global economic down turn that destroyed the world financial market, banking and real estate industries. It leads to the loss of people's life savings, their jobs and homes. It is considered to be the longest period of economic decline since the Great Depression of the 1930s.It arose in the United States of America and Western Europe as a result of the subprime mortgage crisis. Because of the over stress, men begin to exhibit aggressive behaviour to their family members. Moreover, the domestic violence, relationships breakdown and financial problems begin to increase. Poverty arose in suburbs. Murder rate increased up to 15 per cent over the prior year. A large number of incarcerated individuals are released into economically distressed communities. In families, the stress and delays in marriages increased. In educational institutions, the graduation rates and employment of teachers got affected. The inflow of economic migrants to the US across the Mexican border has declined sharply. Old people are encouraged to take early retirement while those who lose their job find particularly hard to re-enter work. The equal pay and sex determination claims made by women have decreased during the Recession period. Critics examined the early 1980s recession in the US and concluded that the overall negative effect was relatively greater for men than for women. There was higher unemployment for white workers rather than black workers and others. Americans are justified in their anxieties regarding love and marriage. The culture of expressive individualism constructed higher expectations on marriage than in the past. It demanded the fulfilment of self-actualization goals. When it is not achieved as expected, it ultimately leads to a greater 2 sense of disappointment. People spent less time in maintaining their relationships during the Recession period. It leads to several problems in marital relationships. The cultural critic, Tom Wolfe said that the period of great economic depression was a self-expressive era. During this era the cultural shift towards consumer narcissism took place. By observing Recession period, Wolfe says that the old alchemical dream was changing base metals into gold. He says that the alchemical dream has capacity to change one's personality. It has ability to remake and remodel one's personality.

\section{AMERICAN DREAM}

The American Dream within consumer culture becomes elusive and an ever-changing product. This consumer narcissism worms its way into marriages by transforming the two partners into consumer subjects. It destroys the self-esteem of each partner. They constantly pitted against the hyper realities glorified by the media. This creates an internal conflict between an individual's desires to find an authentic self. The quest for individualism constructs two diverging paths for men and women. For women, the process is within the context of intimate relationships and for men, it's outside the context of intimate relationships centering on the acquisition of success in the workforce. Contemporary American media dramatized the decline of social rules. It emphasized the rise of the Individual's agency in a consumer-driven culture. The media begins to exhibit a self-centered view of relationships and how it produces a fear of compromising personal desire and emotional ties. Some relationships become deeply rooted in instant gratification without much personal sacrifice.

\section{EXPLORING PERSONALITY DISORDERS}

The plot and characters in the novel represents the psyche of the writer of the novel Paula Hawkins. The Girl on the 
Train, the author may have experienced personality disorders because of the social change during Recession period. The novel tells the story of Rachel Wilson, Megan and Anna about the troubles in the relationship caused by binge drinking and unfaithfulness. The novel begins with the narration of Rachel Wilson, the wife of Tom about her deformed married life. When Rachel could understand that she is incapable to become a mother, out of despair, she started drinking. Tom left her and married Anna. It elevated problems in the existence of Rachel Wilson. She continued drinking and wandering. Hence, she lost her job. While travelling on a train, she begins to observe two attractive couples who live a few houses away from Tom. She named them Jess and Jason. But the real 24 name of the couples whom Rachel idolizes was Megan and Scott. Even though Rachel finds the way of their living attractive, the relationship between Megan and Scott was on the verge of deterioration. Before the marriage to Scott, Megan had a relationship with a person named Mac. They had a child. But out of the carelessness of Megan, the child passed away. This incident created a tremendous impact on Megan's mind. When Scott witnesses his wife, Megan suffering from emotional disturbances, he sends her as a nanny to look after Anna's baby. But Megan started a relationship with Anna's husband, Tom and becomes pregnant. When Megan informed him that she is pregnant, Tom killed Megan to preserve his existing reputation in the society. When Rachel and Anna understand how much Tom was destroying their life through his amorous pursuits. They killed him. The Megan and Rachel is experiencing personality disorders in this novels. Because of their mental unrest, they faced several problems in their life.

Posttraumatic stress disorder (PTSD) is a psychiatric ailment that may happen in people who have encountered or watched a traumatic event such as a natural disaster, a serious accident, a terrorist attack, rape, sexual violence or serious injury. They contemplate the incident frequently and it finally leads to emotional unrest, fear and anger. They may feel detached from society and their companions. They constantly tried to avoid situations or people that remind them of the traumatic event. They show violent and negative reactions to loud noise or an accidental touch. Post traumatic stress disorder could arise in an individual when he learns about the violent death of a close relative in family or friend. The patient with Post traumatic stress disorder would experience sleep difficulties or insomnia and extraordinary tension. In the novel The Girl on the Train, Megan says,

Sometimes I don't even watch the trains go past. I just listen. Sitting here in the morning, eyes closed and the hot sun orange on my eyelids, it could be anywhere. I could be in the south of Spain, at the beach; I could be in Italy, the
Cinque Terre, all those pretty coloured houses and the trains ferrying the tourists back and forth. I could be back in Holkham with the screech of gulls in my ears and salt on my tongue and a ghost train passing on the rusted track half a mile away (25).

The extract reveals that Megan was disturbed by the sound of the train. Showing irritation towards sounds is a symptom of Posttraumatic stress disorder. Megan had several traumatic experiences in her life; these problematic situations are arising from her subconscious mind when she hears the sound of a train. Hence, she tells the ghost train is passing." She flinches every time a train passes jumps when the phone rings. They're just so fragile, aren't they? she says, and I can't disagree with that" (28).

This is another instance that proves Megan had Post traumatic stress disorder. The sound of the phone ringing and the train passing is normal to ordinary people. But for Megan, it is connected to her past life memories. When those past thoughts come to her mind, she feels an extraordinary tension. In the novel, Megan contends:

I've been up for hours; I can't sleep. I haven't slept in days. I hate this, hate Insomnia more than anything, just lying there, brain going round, tick, tick, tick, tick. I itch all over I want to shave my head. I want to run. I want to take a road trip, in a convertible, with the top down. I want to drive to the coast - any coast. I want to walk on a beach (30).

Sleep difficulty or insomnia is another symptom of Posttraumatic stress disorder. Because of her past traumatic memories, she feels a need to shave her head. It seems as if she is experiencing an unusual weight in her head. This condition occurs because of her excessive cross-examination of past life incidents.

Obsessive compulsive disorder is an another form of personality disorder in which the person gives much importance to rules and orderliness. They would show distress if they could not achieve the perfection that they had expected. They would show extreme commitment to work or project by neglecting friends and enjoying activities. They are inflexible about values, ethics and morality. They control their budget and spend money in unwanted situations." I'll wait until the summer is over, then I'll look for work. It seems like a shame to waste these long summer days"(27).

Excessive commitment to work is a symptom of Obsessive-Compulsive Disorder. Even though Dr Kamal had told Megan to take a rest, she keeps on thinking about doing work. She is not ready to waste time. Health is mandatory for human beings while they are suffering from mental unrest, but Megan is not ready to do so. 
The person suffering from Dependent Personality Disorder shows clingy and submissive behaviour towards others. They show the lack of self confidence, the requirement of excessive advice and reassurance from others to make small decisions. They constantly fear disapproval. In the novel, Megan says:

I miss him every day. More than anyone, I think. He's the big hole in my life, in the middle of my soul. Or maybe he was just the beginning of it. I don't know. I don't even know whether all this is really about Ben, or whether it's about everything that happened after that, and everythingthat's happened since. All I know is, one minute I'm ticking along fine and life is sweet and I want for nothing, and the next,I can't wait to get away. I'm all over the place, slipping and sliding again (30).

Megan was greatly affected by her brother's death. She was deeply connected to him. She constantly gets advices from him according to her needs. But when Ben dies, she cannot tolerate it. She feels if there is no one to help her. She used to believe that Ben's death is the trigger that creates problems in her life. Excessive dependence on others and the feeling of the need to be taken care of is a symptom of the Dependence personality disorder. This quote represents Megan's extreme emotional attachment to Ben. Megan says:

We were going to ride motorbikes from Paris to the Coto d'Azur, or all the way down the Pacific coast of the USA, From Seattle to Los Angeles; we were going to follow in Che Guevara's tracks from Buenos Aires to Caracas. Maybe if I'd done all that, I wouldn't have ended up here, not knowing what to do next. Or maybe, if I'd done all that, I'd have ended up exactly where I am and I would be perfectly contented. But I didn't do all that, of course, because Ben never got as far as Paris, he never even made it as far as Cambridge. He died on the A10, his skull crushed beneath the wheels of an articulated lorry (30).

According to social norms, death is a natural process. Usually, when a person's relative dies, he/she will mourn for a certain period of time and he /she will attain emotional stability after that. But the death of Ben is still torturing her even though the accident had happened years before. To Megan, the days with Ben were a sweet memory. They planned to spend time on a road trip and beach. As one of the last sisters that he has, Ben had given Megan attention and protection, especially from the men. But unfortunately, Ben died in a motor accident. Megan had deep sadness because she never expected that her brother will met such a tragic death. Moreover, she saw by herself how the tragic accident happened. From what she experienced, she gets the trauma and stress disorder from the accident.
The person with Schizoid personality disorder has a lack of interest in social or personal relationships. They always prefer to be alone. They appear cold or indifferent towards others. He/she may encounter an inability to pick up normal social cues. Here, we could see Megan showing a desire to remain safe in her house and not to set foot outside the house again. This feeling arises in Megan because of Schizoid personality disorder. In the novel, Megan says;

Sometimes, I don't want to go anywhere, I think I'll be happy if I never had to set foot outside the house again. I don't even miss working. I just want to remain safe and warm in my haven with Scott, undisturbed It help that it's dark and cold and the weather is filthy. It helps that it hasn't stopped raining for weeks - freezing, driving, bitter rain accompanied by gales howling through the trees ( 62 ) .

Because of the disturbed state of mind, Megan retreated from the activities and responsibilities in which she had once taken pleasure. Megan confronts a limited range of care towards her responsibilities. Moreover, she experienced an inability to take pleasures in activities like going outside to spend some time. Similarly, the character named Rachel faced this particular situation. In the beginning of the novel, Rachel says:

The train lurches and sways around the blend, slowing as it approaches a red signal. I try not to look up, I try to read the free newspaper I was handed on my way into the station, but the words blur in front of my eyes, nothing holds my interest. In my head I can still see that little pile of clothes lying at the edge of the track, abandoned (12).

Anhedonia is one of the main symptoms of major depression. Another character in the novel is Rachel Wilson, she experiences this condition. It is the loss of interest in previously rewarding or enjoyable activities. Because of over experience of grief, the person will confront a lack of interest in hobbies, friends, work, food and sex. It's as if the brain's pleasure circuits shut down or short out. Rachel had a habit of reading newspapers. She holds it in her hand as her daily routine. But now she lost interest because of depression caused by an unsatisfied married relationship. Depression reduces the hedonic capacity of the body. This can be tracked from her voice.

The person with Histrionic Personality Disorder is excessively dramatic, emotional and sexually provocative. They speak dramatically the strong opinions. Because of their rapid changing emotions, they demonstrate the unpredictable behaviour. Megan had desired to get the attention of men. She sought care and love from them. But unfortunately, she didn't get what she expected from them. Mac was the boyfriend of Megan before she got married to Scott. Scott usually goes to work leaving Megan. When 
Scott does so, she feels that he is avoiding him. "Scott isn't home when I get back, so I get my laptop out and google him, for the First Time ever. For first time in a decade, I look for Mac" (65).

Mac was the boyfriend of Megan. The accidental death of Megan's child with Mac by her carelessness destroyed the relationship between them. Mac deserted her for this reason. They had drifted apart years before. But when Megan encounters the lack of attention from Scott, she tried to contact Mac. From this, it is evident that Megan has no emotional stability to face rejection or criticism. The fear of disapproval, rejection and ridicule are the symptoms of Histrionic personality disorder. Hence, we can conclude that Megan had a Histrionic personality disorder.

The person with antisocial personality behaviour disregarded for others needs or feeling. They would create a recurrent problem with the law. The main characteristic feature of them is the consistent irresponsibility. Even though these kinds of people know they are not giving importance to others feelings, they lack remorse. Megan drifted apart from laws and orders in society. She feels as if she is trapped in a flawed society. Hence, she was consistently irresponsible as a daughter and wife. She violated civil law by committing theft. She disappointed her parents and transgressed the ordinary family. "She ran away from home three days after his funeral. She was arrested twice-once for theft and once for splitting" (92).

Megan destroyed the sacred relationship with her parents because of her emotional instability. The death of Ben was so hard for her to tolerate. In order to avoid memories of Ben from her life, she desired to be alone. Megan's detachment from her parents pricked their mind. The parents of Megan died without reconciliation with their daughter. It means that Megan had never tried to contact them after she left from her house. When Megan shows a lack of interest in social or personal relationships, we can trace antisocial personality disorder in her. "I lay there and I thought of what that teacher said, and of all the things I'd been: child, rebellious teenager, runaway, whore, lover, bad mother, bad wife" (282).

When Megan thinks about her past life, she feels as if she destroyed her life by reckless living style. Self-loathing can be traced in her words. This condition is the trace of avoidance personality disorder. Because the person with this personality disorder has an inferiority complex. They always believe that they are doing everything in the wrong direction. "He grabbed hold of my shoulder, his thumbs digging into the flesh at the top of my arms, and told me to calm down, to stop behaving like a child" (137).

Megan's impulsive behaviour can be observed through this statement. When Dr Kamal told her that he cannot continue the relationship with her. She becomes angry and kissed him violently. It motivated Dr Kamal to push her away. From these circumstances, it is evident that Megan had an unreasonable expectation of affection from him. Dr Kamal had shown love and care to Megan as a part of treatment. But Megan misrecognized it as romantic love. Even though Kamal says that if she continues to try to have a relationship, it would affect his career and reputation bitterly. But Megan was not ready to accept the fact. The failure to recognize others need and feelings, fantasies about power, success, attractiveness and expectation of constant affection praise and admiration from others are the symptoms of a Narcissistic personality disorder. We can trace this disorder in Megan. In the novel, Megan says:

I'd just walk around those dark rooms and I'd hear her crying. I'd smell her skin. I saw things. I'd wake in the night and be sure that there was someone else- something else - in the house with me. I thought I wasgoing mad. I thought I was going to die. I thought that maybe I would just stay there, and that one day someone would find me. At least that way I wouldn't have left her. (210).

After the death of her child, Mac left her. The memories of her child haunted her. She feels the presence of Libby there. Her child was buried near the house, but yet she senses Libby in her room. She feels as if hearing the cry of her child. She experiences extreme tension. The odd perceptual experiences such as hearing a voice are the symptoms of Schizotypal personality disorder. Megan hears the sound of Libby in her room. even though she is buried in the grave. When Mac left her during that problematic situation, her condition becomes worse. In the novel, Megan says:

I can't hate her, but she scares me. I'm afraid of what she'll do to me, or what I'll do to her. It's that fear that woke me just after five this morning, soaked in sweat despite the open windows and the fact that I'm alone. Scott's at a conference, somewhere in Hertfordshire or Essex or somewhere. He's back tonight (279).

This is another instance in which Megan gets frustrated by her dead child. A constant guilty feeling haunted her. Because of fear, she wakes up at five in the morning. In the novel, Megan says:

I go after him, walking quickly at first and then running, and when I get close enough I shove him in the back. I'm yelling at him, screaming, trying to scratch his fucking smug face and he's laughing, fending me off with ease. I start saying the worst things I can think of. I insult his manhood, his boring wife, his ugly child (299).

Tom abused Megan and makes her pregnant. When Megan says to Tom. Without any emotion, he motivated her to do 
an abortion. But Megan was not ready to do so. She pleaded before him. But Tom dismissed her brutally. It caused her to tell him. Out of rage, she tells him that she is not going away and makes him pay for this. Hearing these words, Tom attacked Megan and killed her. When Tom rejected her, it was too much for her to bear, she continued to plead before a cruel man. She feels that without him, she cannot exist anymore. Because of her dependent personality disorder, Megan's life ends up in the hands of Tom.

\section{CONCLUSION}

In this novel, we could see how the conflict between Id, Ego and Superego affected Megan and Rachel. Megan's actions were motivated by Id. she gives much importance to sexual pleasures. She created an illogical relationship with several men. The unbridled passion reigned her heart than reason. If finally leads to her death. She suppressed her Ego. She ignored the messages that she gets from her inner conscience and it eventually leads to her death. Rachel was under the control of a Superego, her head was equipped with justice and moral ideas related to a perfect married relationship. When Rachel witness Tom's illegal affair with Anna, it creates rage in her heart. When she realizes that Megan was killed by Tom, she was not ready to pardon Tom no more. Hence, she killed him. Therefore, It can be understand that the personality disorder happens due to the constant conflict of Id, Ego and Superego. The novels which exhibit psychic disorders was common in the Recession period. The character named Amy in Gone Girl can be compared with Rachel and Megan in The Girl on the Train.

Paula Hawkins represented the toxic effects of personality disorders in The Girl on the Train through Megan. Megan experienced Post Traumatic Stress Disorder, ObsessiveCompulsive Disorder, Histrionic Personality disorder and antisocial personality disorder. Thus, Paula Hawkins had expressed it through an ambiguous style of narration by the novel The Girl on the Train.

\section{REFERENCES}

[1] Akhtar, Salman. Comprehensive Dictionary of Psychoanalysis. Studio Publishing Services, 2009.

[2] Bancroft, Colette." Interview: Paula Hawkins on Girl on the Train and the new Into the Water." Tampa Bay Times, Tampa Bay Times, Inc., 12 May 2017, www.tampabay.co $\quad \mathrm{m} /$ features/books/interview-paulahawkins-on-girl-on-the-train-and-the-newinto-thewater/2323430/.

[3] Christie, Daniel. "Peace Psychology for a Peaceful World". American Psychologist, vol.63, no.6, September 2008, pp.540-552.
[4] Hawkins, Paula. The Girl on the Train. Replika P, 2015. 